\title{
Role of the Promoter Polymorphism IL-6 -174G/C in Dermatomyositis and Systemic Lupus Erythematosus
}

\author{
Maria Hristova, ${ }^{1}$ Lyubomir Dourmishev, ${ }^{2}$ Zornitsa Kamenarska, ${ }^{3,4}$ Svetla Nikolova, ${ }^{3,4}$ \\ Radka Kaneva, ${ }^{3,4}$ Anton Vinkov, ${ }^{5}$ Marta Baleva, ${ }^{1}$ Daniela Monova, ${ }^{6}$ and Vanio Mitev ${ }^{3,4}$ \\ ${ }^{1}$ Department of Clinical Laboratory and Clinical Immunology, Medical University-Sofia, 1 Georgi Sofijski Street, 1431 Sofia, Bulgaria \\ ${ }^{2}$ Department of Dermatology and Venereology, Medical University-Sofia, 1 Georgi Sofijski Street, 1431 Sofia, Bulgaria \\ ${ }^{3}$ Molecular Medicine Center, Medical University-Sofia, 2 Zdrave Street, 1431 Sofia, Bulgaria \\ ${ }^{4}$ Department of Medical Chemistry and Biochemistry, Medical University-Sofia, 2 Zdrave Street, 1431 Sofia, Bulgaria \\ ${ }^{5} 28$ Diagnostic and Consultative Center-Sofia, 1 Iliya Beshkov Street, 1592 Sofia, Bulgaria \\ ${ }^{6}$ Department of Nephrology, Ministry of Interior Hospital, 79 Skobelev Boulevard, 1606 Sofia, Bulgaria
}

Correspondence should be addressed to Zornitsa Kamenarska; kamenarska@yahoo.com

Received 29 April 2013; Revised 29 July 2013; Accepted 12 August 2013

Academic Editor: Tomoshige Kino

Copyright (C) 2013 Maria Hristova et al. This is an open access article distributed under the Creative Commons Attribution License, which permits unrestricted use, distribution, and reproduction in any medium, provided the original work is properly cited.

The promoter polymorphism -174G/C within the interleukin-6 gene (IL-6) has been reported to have a functional importance through the modulation of IL-6 gene expression in vitro and in vivo. IL-6 is thought to play an important role in autoimmune diseases and the effect of its receptor inhibitor-tocilizumab-has been recently studied. The aim of this case-control study was to investigate the association between the interleukin-6 -174G/C single nucleotide polymorphism and the susceptibility to dermatomyositis (DM) and systemic lupus erythematosus (SLE) in Bulgarian patients. Altogether, 87 patients-52 with SLE and 35 with DM-as well as 80 unrelated healthy controls were included in this study. All of them were analyzed by restriction fragment length polymorphism analysis (RFLP). The GG genotype and the G allele appeared to be associated with SLE, especially in women. None of the genotypes showed an association with DM. However, the G allele appeared to be associated with muscle weakness and it is a risk factor for elevated muscle enzymes. Our results indicate that IL-6 -174G/C polymorphism might be associated with the susceptibility to SLE especially in women. Although it is not associated with DM, it seems that IL-6-174G/C polymorphism could modulate some clinical features in the autoimmune myopathies.

\section{Introduction}

Dermatomyositis (DM) and systemic lupus erythematosus (SLE) are diseases of unknown etiology. However, the dysregulation of cytokine production or action is thought to have an important role in their development [1]. The cytokine secretion was found to be under genetic control [2]. In our previous study, we have found association between TNF- $\alpha$ polymorphisms and the etiology of DM and SLE in Bulgarian patients [3].

TNF- $\alpha$ and IL- 1 can induce IL- 6 and IL- 6 induces B-cell differentiation to plasma cells, hyperactivity, and secretion of antibodies and also promotes T-cell proliferation, cytotoxic T-cell differentiation, and local inflammation. According to Linker-Israeli et al. [4], elevated plasma levels of IL-6 messenger-RNA and protein could be detected in SLE patients. Serum TNF- $\alpha$ and IL- 6 levels were reported to be sensitive markers for SLE activity [5, 6]. IL-6 is also considered to play a role in the development of DM, since it leads to reduced myogenesis [7]. Hagiwara et al. [8] have found that patients with DM and polymyositis have an increased number of IL-6 secreting cells compared to controls. Bilgic et al. [9] suggest that IL-6 serum level is a candidate biomarker for disease activity in both adult and juvenile DM.

The G allele of the IL- $6-174 \mathrm{G} / \mathrm{C}$ polymorphism is associated with higher IL-6 expression [10]. The presence of the G allele has been associated with poor outcome in a variety of diseases including coronary artery disease [11], more severe 
TABLE 1: Demographic and clinical data.

\begin{tabular}{|c|c|c|c|c|}
\hline \multirow{3}{*}{$\begin{array}{l}\text { Disease } \\
\text { Demographic parameters }\end{array}$} & \multicolumn{2}{|l|}{$\mathrm{DM}$} & \multicolumn{2}{|c|}{ SLE } \\
\hline & Female/male & $22 / 13$ & Female/male & $43 / 9$ \\
\hline & Age, mean \pm SD years & $52 \pm 14.7$ & Age, mean \pm SD years & $40 \pm 12.4$ \\
\hline \multirow{11}{*}{ Clinical parameters } & Cutaneous disease & $27(77.1 \%)$ & Malar rash & $34(65.4 \%)$ \\
\hline & Muscle weakness & $28(80.0 \%)$ & Discoid rash & $9(17.3 \%)$ \\
\hline & Elevated muscle enzymes & $19(54.3 \%)$ & Arthritis & $34(65.4 \%)$ \\
\hline & EMG findings & $20(57.1 \%)$ & Oral ulcer & $3(5.8 \%)$ \\
\hline & Photosensitivity & $21(60.0 \%)$ & Photosensitivity & $30(57.7 \%)$ \\
\hline & Immunological disease & $9(25.7 \%)$ & Serositis & $11(21.2 \%)$ \\
\hline & & & Renal disease & $52(100 \%)$ \\
\hline & & & Neurological disease & $10(19.2 \%)$ \\
\hline & & & Haematological disease & $20(38.5 \%)$ \\
\hline & & & Immunological disease & $32(61.5 \%)$ \\
\hline & & & ANA & $36(69.2 \%)$ \\
\hline
\end{tabular}

manifestations of the Sjögren's syndrome [12] and systemic sclerosis [13], increased risk of juvenile rheumatoid arthritis [10], and growth retardation of children with Crohn's disease [14]. It was recently found that the IL-6 -174G/C gene promoter polymorphism predicts therapeutic response to TNF- $\alpha$ blockers [15].

The objective of our pilot study was to determine whether the IL-6 -174G/C polymorphism is a risk factor for the development of adult DM and SLE in Bulgarian patients and to define its contribution to the increased risk.

\section{Materials and Methods}

2.1. Clinical Material. Thirty-five patients with dermatomyositis who met the criteria of Bohan and Peter [16, 17] and Targoff et al. [18] and fifty-two with systemic lupus erythematosus who met the American College of Rheumatology (ACR) criteria were included in this study. The clinical and demographic data are presented in Table 1. In the DM group, 22 patients were females and 13 males. The mean age was 52 with a range of $18-82$ years. In five patients, DM was associated with malignancy (breast and gastric carcinomas, myeloma and seminoma). In the SLE group, 43 were females and 9 males. The mean age was 40 with a range of 15-78 years. All of them showed renal involvement to a different extent. The patients have been followed for a mean of 10 years at the Department of Dermatology and Venereology, Medical University-Sofia, at the Department of Nephrology, Medical University-Sofia and at the Department of Nephrology, Ministry of Interior Hospital-Sofia.

The control group consisted of 80 anonymous healthy volunteers who did not show any clinical or laboratory signs of autoimmune skin diseases, as well as kinship with patients suffering from autoimmune skin diseases. They were randomly selected from the Biobank of the Molecular Medicine Center and the National Genetic Laboratory as to match the patients in age, gender, and ethnicity. The mean age was $45 \pm 13.8$ with a range of 19-76.
2.2. Genetic Analysis. The scientific investigation presented in this paper has been carried out in accordance with The Code of Ethics of the World Medical Association (Declaration of Helsinki) for experiments involving humans. The study was approved by the local ethics committee at the Medical University-Sofia. All participants signed an informed consent and venous blood was drawn for DNA isolation. Genomic DNA was extracted from the peripheral blood with the Chemagen DNA purification kit, using Chemagic Magnetic Separation Module I (Chemagen AG).

The analysis of IL-6 -174G/C polymorphism was performed as previously described by Libra et al. [19].

2.3. Statistical Analysis. Allele and genotype frequencies were compared between DM and SLE cases and controls, using Fisher's exact test to calculate $P$ values for $2 \times 2$ tables. Where significant, data were expressed as $P$ value and odds ratios (OR) with exact $95 \%$ confidence intervals (CI). Bonferroni correction was applied with a threshold significance level of 0.01. The test for Hardy-Weinberg equilibrium was done by $\chi^{2}$ statistics.

\section{Results}

The single nucleotide polymorphism (SNP) was found to be in Hardy-Weinberg equilibrium. The observed allele and genotype frequencies of the IL-6 -174G/C polymorphism among the patients with DM and SLE and the healthy controls are summarized in Table 1.

The frequency of the GG genotype was higher among SLE patients (55.8\%) compared to controls (40.0\%) and it is associated with an increased $\mathrm{OR}(P=0.055$, after Bonferroni correction $P=0.28$, OR 1.9; 95\% CI 0.9-3; Table 2). Stratification by gender led to a stronger association of the GG genotype with SLE in women $(P=0.008$, after Bonferroni correction $P=0.04$, OR 2.9, 95\% CI 1.3-6.6; Table 3). No difference was found in the genotype distribution between 
TABLE 2: Genotype and allele frequencies of IL-6 -174G/C polymorphism in dermatomyositis and systemic lupus erythematosus patients and controls.

\begin{tabular}{cccc}
\hline $\begin{array}{l}\text { Genotype } \\
\begin{array}{l}N=\text { number } \\
\text { of patients }\end{array}\end{array}$ & DM & SLE & Controls \\
\hline$-174 \mathrm{G} / \mathrm{C}$ & $N=52$ & $N=80$ \\
GG & $14(40.0 \%)$ & $29(55.8 \%)$ & $32(40.0 \%)$ \\
GC & $11(31.4 \%)$ & $13(25.0 \%)$ & $21(26.3 \%)$ \\
CC & $10(28.6 \%)$ & $10(19.2 \%)$ & $27(33.7 \%)$ \\
G & $55.7 \%$ & $68.3 \%$ & $53.1 \%$ \\
C & $44.3 \%$ & $34.6 \%$ & $46.9 \%$ \\
$P$ value & NS & $\mathbf{G}-\boldsymbol{P}=\mathbf{0 . 0 1}$ & \\
\hline
\end{tabular}

${ }^{*}$ Not significant.

TABLE 3: Allele and genotype frequency of the IL-6 -174G/C polymorphism in females with dermatomyositis and systemic lupus erythematosus and in controls.

\begin{tabular}{cccc}
\hline $\begin{array}{l}\text { Genotype } \\
\begin{array}{l}N=\text { number of } \\
\text { females }\end{array}\end{array}$ & DM & SLE & Controls \\
\hline$-174 \mathrm{G} / \mathrm{C}$ & $N=43$ & $N=58$ \\
GG & $8(36.4 \%)$ & $26(60.5 \%)$ & $20(34.5 \%)$ \\
GC & $6(27.2 \%)$ & $10(23.2 \%)$ & $14(24.1 \%)$ \\
CC & $8(36.4 \%)$ & $7(16.3 \%)$ & $24(41.4 \%)$ \\
G & $50.0 \%$ & $72.1 \%$ & $46.6 \%$ \\
C & $50.0 \%$ & $27.9 \%$ & $53.4 \%$ \\
$P$ value & NS* & GG-0.008; & \\
\hline
\end{tabular}

${ }^{*}$ Not significant.

DM patients and controls. Stratification by gender did not lead to any statistically significant results.

The $\mathrm{G}$ allele showed an association with SLE $(P=0.01$, after Bonferroni correction $P=0.05$, OR 1.9, 95\% CI 1.1-3.2; Table 2). Stratification by gender led to a stronger association of the G allele with SLE in women $(P=0.0002$, after Bonferroni correction $P=0.001, \mathrm{OR}=3,95 \%$ CI 1.6-5.4; Table 3). No significant increase of the $G$ allele was found in the DM group versus controls (Table 2), and stratification by gender did not lead to any statistically significant results (Table 3).

No association was found between the $-174 \mathrm{G} / \mathrm{C}$ polymorphism and SLE clinical features (Table 4).

An association was found between the GG and GC genotypes and the G allele with muscle weakness (GG + GC$P=0.012$, after Bonferroni correction $P=0.06$, OR 11.5, 95\% CI 1.7-77.2; G-P $=0.023$, after Bonferroni correction $P=0.12$, OR 4.2, 95\% CI 1.2-15; Table 5) and the elevated muscle enzymes (GG $+\mathrm{GC}-P=0.013$, after Bonferroni correction $P=0.065$, OR $8.5,95 \%$ CI 1.5-49.5; G-P $=0.054$, after Bonferroni correction $P=0.27$, OR 2.5, 95\% CI 0.9-6.5; Table 5) in DM patients.

\section{Discussion}

From all polymorphisms within the IL-6 gene, the promoter polymorphism $-174 \mathrm{G} / \mathrm{C}$ seems to be of greatest significance for the development of autoimmune diseases. However, the results published so far in the literature are rather conflicting.

In our study, no association was found between the GG genotypes and DM but its frequency was higher among the SLE patients compared to the controls and it is associated with an increased OR. Stratification by gender led to a stronger association of the GG genotype with SLE in women. The association remained statistically significant after the application of Bonferroni correction. The GG genotype was earlier found to be increased in Egyptian [20] and Malaysian [21] patients with SLE but no significant differences in the genotype frequencies were found between German patients and healthy controls [22]. There were no significant differences in the genotype frequencies between Portuguese [23] and Chinese [24] patients with SLE either. Probably such differences could be explained with population variations [25]. In our study, no marked increase of the GC genotype was observed among the controls but such elevation was earlier found among Egyptian [20] and Malaysian [21] controls. Chua et al. [21] suggested that the $\mathrm{C}$ allele might have a masking effect on the $\mathrm{G}$ allele when both alleles are present in heterozygous individuals. However, they have not observed any significant association of the homozygous $\mathrm{C}$ allele with the onset of SLE or with protection from the disease.

In our study, the $G$ allele showed an association with SLE. Stratification by gender led to a stronger association of the G allele with SLE in women. The associations remained significant after the application of Bonferroni correction. No significant increase of the $G$ allele was found in the DM group versus controls, and stratification by gender did not lead to any statistically significant results. Earlier studies showed no significant differences in allele frequencies between German SLE patients and healthy controls [22]. There were no significant differences in the allele frequencies between Portuguese [23] and Chinese [24] patients with SLE either. However, our results are in line with the results of a recent meta-analysis which proved that the $-174 \mathrm{G}$ allele is associated with SLE mainly in the European populations and less with SLE in the Asian ones [26].

Earlier study of the relationship between $-174 \mathrm{G} / \mathrm{C}$ polymorphism and clinical manifestations and laboratory parameters showed an association between the G allele and the presence of anti-nuclear antibodies in all patients and rash and hematuria in male patients with SLE [27]. By comparing patients with various disease manifestations, Schotte et al. [22] found an association of the $-174 \mathrm{G}$ allele with discoid skin lesions and anti-histone antibodies. Hamdy et al. [20] reported a statistically significant increase of the GG genotype with pulmonal affection, nephritis, and arthritis. The SLE patients with GG genotype showed significantly higher frequencies and increased risk of constitutional manifestations at disease onset, photosensitivity, hematological disorders, and positivity of ANA and anti-dsDNA [27]. Quite surprisingly, Santos et al. [23] found the -174CC genotype but not the GG genotype to be independently associated with renal 
TABLE 4: Comparison between the genotypes and ACR criteria.

\begin{tabular}{|c|c|c|c|c|}
\hline Genotype & GG $(n=29)$ & $\mathrm{GC}(n=13)$ & $\mathrm{CC}(n=10)$ & $P$ value \\
\hline Malar rash & $20(69.0 \%)$ & $5(38.5 \%)$ & $9(90.0 \%)$ & $\mathrm{NS}^{*}$ \\
\hline Discoid rash & $6(20.7 \%)$ & $3(23.1 \%)$ & $0(0.0 \%)$ & NS \\
\hline Photosensitivity & $17(58.6 \%)$ & $8(61.5 \%)$ & $5(50.0 \%)$ & NS \\
\hline Oral ulcer & $1(3.4 \%)$ & $2(15.4 \%)$ & $0(0.0 \%)$ & NS \\
\hline Arthritis & $18(56.5 \%)$ & $9(69.2 \%)$ & $7(70.0 \%)$ & NS \\
\hline Serositis & $6(20.7 \%)$ & $4(30.8 \%)$ & $1(10.0 \%)$ & NS \\
\hline Renal disease & $29(100.0 \%)$ & $13(100.0 \%)$ & $10(100.0 \%)$ & - \\
\hline Neurological disease & $6(26.1 \%)$ & $2(15.4 \%)$ & $2(20.0 \%)$ & NS \\
\hline Haematological disease & $11(37.9 \%)$ & $4(30.8 \%)$ & $5(50.0 \%)$ & NS \\
\hline Immunological disease (anti-dsDNA, anti-Sm, and antiphospholipid Ab) & $20(69.0 \%)$ & $6(46.2 \%)$ & $6(60.0 \%)$ & NS \\
\hline ANA & $22(75.9 \%)$ & $7(53.8 \%)$ & $7(70.0 \%)$ & NS \\
\hline
\end{tabular}

${ }^{*}$ Not significant.

TABLE 5: Comparison between the genotypes and DM clinical parameters.

\begin{tabular}{|c|c|c|c|c|}
\hline Genotype & $\mathrm{GG}(n=14)$ & $\mathrm{GC}(n=11)$ & $\mathrm{CC}(n=10)$ & $P$ value \\
\hline Muscle weakness & $12(85.7 \%)$ & $11(100.0 \%)$ & $5(50.0 \%)$ & $\mathrm{GG}+\mathrm{GC}-P=0.012, \mathrm{G}-P=0.023$ \\
\hline Elevated muscle enzymes & $8(57.1 \%)$ & $9(81.8 \%)$ & $2(20.0 \%)$ & $\mathrm{GG}+\mathrm{GC}-P=0.013, \mathrm{G}-P=0.054$ \\
\hline EMG findings & $7(50.0 \%)$ & $8(72.7 \%)$ & $5(50.0 \%)$ & $\mathrm{NS}^{*}$ \\
\hline Cutaneous disease & $11(78.6 \%)$ & $9(81.8 \%)$ & $7(70.0 \%)$ & NS \\
\hline Photosensitivity & $10(71.4 \%)$ & $6(54.5 \%)$ & $5(50.0 \%)$ & NS \\
\hline Immunological disease (anti-myositis-specific antibodies) & $3(21.4 \%)$ & $4(36.4 \%)$ & $2(20.0 \%)$ & NS \\
\hline
\end{tabular}

* Not significant.

disease and the $\mathrm{C}$ allele with the presence of irreversible damage. Huang et al. [24] did not detect any association between the IL- 6 genotype and clinical or laboratory profiles in SLE patients. Similarly to the results of Huang et al. [24], we found no relationship between the $-174 \mathrm{G} / \mathrm{C}$ polymorphism and ACR criteria. Although the statistical significance was lost when Bonferroni correction was applied, an increased frequency of the GG and GC genotypes and the G allele was found in DM patients with muscle weakness and elevated muscle enzymes which is in line with the role of IL-6 as a myokine. Our results confirm other authors' findings that the elevated levels of IL-6 lead to muscle weakness [28, 29]. To the best of our knowledge, this is the first study that investigates the IL-6 -174G/C polymorphism in patients with DM.

The major limitation of our study is the small sample size which could affect the statistical power of the results. Obviously, more studies in a larger cohort are needed to clarify the role of this polymorphism for the susceptibility and clinical manifestations of SLE and DM.

In conclusion, our results show that the IL-6 -174G/C polymorphism might be associated with SLE mainly in women. The GG genotype and G allele might be associated with DM clinical features.

\section{Conflict of Interests}

The authors state no conflict of interests.

\section{Authors' Contribution}

Lyubomir Dourmishev and Zornitsa Kamenarska contributed equally to this work.

\section{Acknowledgments}

The genetic analysis was performed at the Molecular Medicine Center, Medical University, Sofia, supported by an infrastructure Grant DUNK01-2/2009 by the National Science Fund, Ministry of Education, Youth and Science. The authors are grateful to Professor B. Bogov, Dr. A. Iliev (Alexandrovska Hospital), and Dr. E. Peneva (Ministry of Interior Hospital) for their support in the recruitment of the SLE patients.

\section{References}

[1] J. J. O’Shea, A. Ma, and P. Lipsky, "Cytokines and autoimmunity," Nature Reviews Immunology, vol. 2, no. 1, pp. 37-45, 2002.

[2] A. Pawlik, M. Baskiewicz-Masiuk, B. Machalinski, and B. Gawronska-Szklarz, "Association of cytokine gene polymorphisms and the release of cytokines from peripheral blood mononuclear cells treated with methotrexate and dexamethasone," International Immunopharmacology, vol. 6, no. 3, pp. 351357, 2006.

[3] L. Dourmishev, Z. Kamenarska, M. Hristova, R. Dodova, R. Kaneva, and V. Mitev, "Association of TNF- $\alpha$ polymorphisms with adult dermatomyositis and systemic lupus erythematosus 
in Bulgarian patients," International Journal of Dermatology, vol. 51, no. 12, pp. 1467-1473, 2012.

[4] M. Linker-Israeli, D. J. Wallace, J. Prehn et al., "Association of IL-6 gene alleles with systemic lupus erythematosus (SLE) and with elevated IL-6 expression," Genes and Immunity, vol. 1, no. 1, pp. 45-52, 1999.

[5] A. Sabry, H. A. Sheashaa, A. El-Husseini et al., "Proinflammatory cytokines (TNF- $\alpha$ and IL-6) in Egyptian patients with SLE: Its correlation with disease activity," Cytokine, vol. 35, no. 3-4, pp. 148-153, 2006.

[6] A. Sabry, S. R. Elbasyouni, H. A. Sheashaa et al., "Correlation between levels of TNF-alpha; and IL-6 and hematological involvement in SLE Egyptian Patients with lupus nephritis," International Urology and Nephrology, vol. 38, no. 3-4, pp. 731737, 2006.

[7] R. C. J. Langen, A. M. W. J. Schols, M. C. J. M. Kelders, J. L. J. van der Velden, E. F. M. Wouters, and Y. M. W. Janssen-Heininger, "Tumor necrosis factor- $\alpha$ inhibits myogenesis through redoxdependent and -independent pathways," American Journal of Physiology, vol. 283, no. 3, pp. C714-C721, 2002.

[8] E. Hagiwara, E. M. Adams, P. H. Plotz, and D. M. Klinman, "Abnormal numbers of cytokine producing cells in patients with polymyositis and dermatomyositis," Clinical and Experimental Rheumatology, vol. 14, no. 5, pp. 485-491, 1996.

[9] H. Bilgic, S. R. Ytterberg, S. Amin et al., "Interleukin-6 and type I interferon-regulated genes and chemokines Mark disease activity in dermatomyositis," Arthritis and Rheumatism, vol. 60, no. 11, pp. 3436-3446, 2009.

[10] D. Fishman, G. Faulds, R. Jeffey et al., "The effect of novel polymorphisms in the interleukin-6 (IL-6) gene on IL-6 transcription and plasma IL-6 levels, and an association with systemic- onset juvenile chronic arthritis," The Journal of Clinical Investigation, vol. 102, no. 7, pp. 1369-1376, 1998.

[11] S. E. Humphries, L. A. Luong, M. S. Ogg, E. Hawe, and G. J. Miller, "The interleukin-6 -174G/C promoter polymorphism is associated with risk of coronary heart disease and systolic blood pressure in healthy men," European Heart Journal, vol. 22, no. 24, pp. 2243-2252, 2001.

[12] J. Hulkkonen, M. Pertovaara, J. Antonen, A. Pasternack, and M. Hurme, "Elevated interleukin-6 plasma levels are regulated by the promoter region polymorphism of the IL6 gene in primary Sjögren's syndrome and correlate with the clinical manifestations of the disease," Rheumatology, vol. 40, no. 6, pp. 656-661, 2001.

[13] R. Sfrent-Cornateanu, C. Mihai, S. Balan, R. Ionescu, and E. Moldoveanu, "The IL-6 promoter polymorphism is associated with disease activity and disability in systemic sclerosis," Journal of Cellular and Molecular Medicine, vol. 10, no. 4, pp. 955-959, 2006.

[14] A. Sawczenko, O. Azooz, J. Paraszczuk et al., "Intestinal inflammation-induced growth retardation acts through IL-6 in rats and depends on the -174 IL- 6 G/C polymorphism in children," Proceedings of the National Academy of Sciences of the United States of America, vol. 102, no. 37, pp. 13260-13265, 2005.

[15] L. di Renzo, A. Bianchi, R. Saraceno et al., “-174G/C IL-6 gene promoter polymorphism predicts therapeutic response to TNF$\alpha$ blockers," Pharmacogenetics and Genomics, vol. 22, no. 2, pp. 134-142, 2012.

[16] A. Bohan and J. B. Peter, "Polymyositis and dermatomyositis I," The New England Journal of Medicine, vol. 292, no. 7, pp. 344347, 1975.
[17] A. Bohan and J. B. Peter, "Polymyositis and dermatomyositis II," The New England Journal of Medicine, vol. 292, no. 8, pp. 403407, 1975.

[18] I. N. Targoff, F. W. Miller, T. A. Medsger Jr., and C. V. Oddis, "Classification criteria for the idiopathic inflammatory myopathies," Current Opinion in Rheumatology, vol. 9, no. 6, pp. 527-535, 1997.

[19] M. Libra, S. S. Signorelli, Y. Bevelacqua et al., "Analysis of G(-174)C IL-6 polymorphism and plasma concentrations of inflammatory markers in patients with type 2 diabetes and peripheral arterial disease," Journal of Clinical Pathology, vol. 59, no. 2, pp. 211-215, 2006.

[20] E. Hamdy, R. A. Afify, A. Kamal, D. Abass, and M. Mahmoud, "IL-6 promoter polymorphism (-174G/C) and systemic lupus erythematosus," Comperative Clinical Pathology, vol. 21, no. 5, pp. 975-979, 2012.

[21] K. H. Chua, B. P. Kee, S. Y. Tan, and L. H. Lian, "Interleukin-6 promoter polymorphisms $(-174 \mathrm{G} / \mathrm{C})$ in Malaysian patients with systemic lupus erythematosus," Brazilian Journal of Medical and Biological Research, vol. 42, no. 6, pp. 551-555, 2009.

[22] H. Schotte, B. Schlüter, S. Rust, G. Assmann, W. Domschke, and M. Gaubitz, "Interleukin-6 promoter polymorphism ($174 \mathrm{G} / \mathrm{C}$ ) in Caucasian German patients with systemic lupus erythematosus," Rheumatology, vol. 40, no. 4, pp. 393-400, 2001.

[23] M. J. Santos, D. Fernandes, S. Capela, J. C. da Silva, and J. E. Fonseca, "Interleukin-6 promoter polymorphism -174G/C is associated with nephritis in Portuguese Caucasian systemic lupus erythematosus patients," Clinical Rheumatology, vol. 30, no. 3, pp. 409-413, 2011.

[24] C.-M. Huang, A.-P. Huo, C.-H. Tsai, C.-L. Chen, and F.-J. Tsai, "Lack of association of interleukin- 6 and interleukin-8 gene polymorphisms in Chinese patients with systemic lupus erythematosus," Journal of Clinical Laboratory Analysis, vol. 20, no. 6, pp. 255-259, 2006.

[25] S. A. Borinskaya, A. S. Gureev, A. A. Orlova et al., "Allele frequency distributions of $-174 \mathrm{G} / \mathrm{C}$ polymorphism in regulatory region of interleukin 6 gene (IL6) in Russian and worldwide populations," Russian Journal of Genetics, vol. 49, no. 1, pp. 98109, 2013.

[26] Y. H. Lee, H. S. Lee, S. J. Choi, J. D. Ji, and G. G. Song, "The association between interleukin-6 polymorphisms and systemic lupus erythematosus: a meta-analysis," Lupus, vol. 21, no. 1, pp. 60-67, 2012.

[27] E. M. Godarzi, E. K. Sarvestani, E. Aflaki, and Z. Amirghofran, "Interleukin-6 gene polymorphism in Iranian patients with systemic lupus erythematosus," Clinical Rheumatology, vol. 30, no. 2, pp. 179-184, 2011.

[28] L. A. Schaap, S. M. F. Pluijm, D. J. H. Deeg, and M. Visser, "Inflammatory markers and loss of muscle mass (sarcopenia) and strength," The American Journal of Medicine, vol. 119, no. 6, pp. 526.e9-526.e17, 2006.

[29] F. Haddad, F. Zaldivar, D. M. Cooper, and G. R. Adams, "IL-6induced skeletal muscle atrophy," Journal of Applied Physiology, vol. 98, no. 3, pp. 911-917, 2005. 


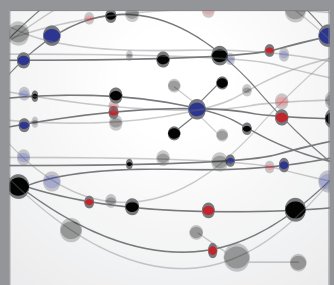

The Scientific World Journal
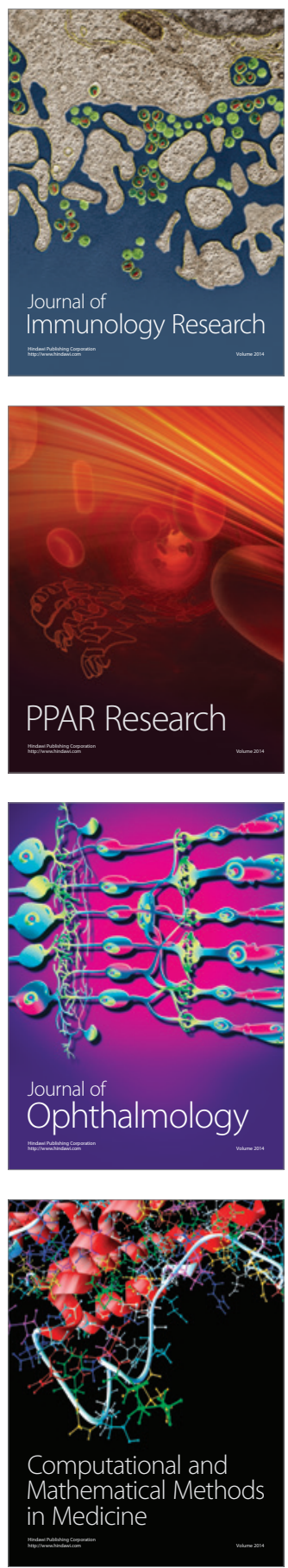

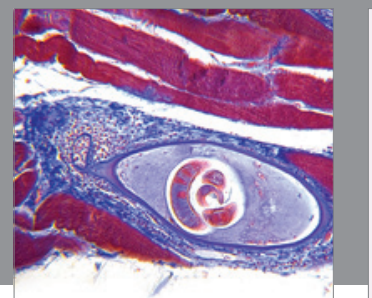

Gastroenterology

Research and Practice
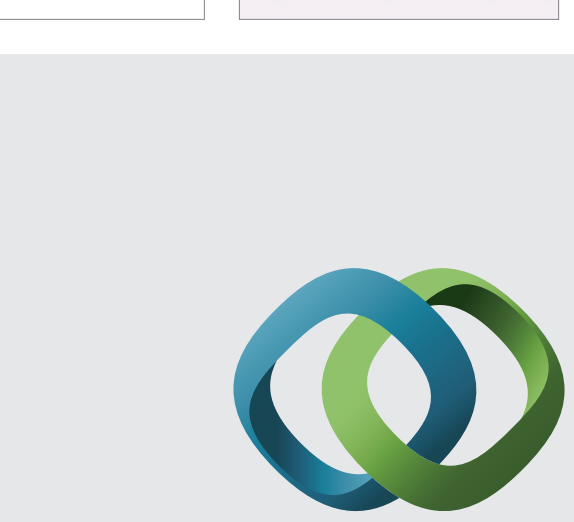

\section{Hindawi}

Submit your manuscripts at

http://www.hindawi.com
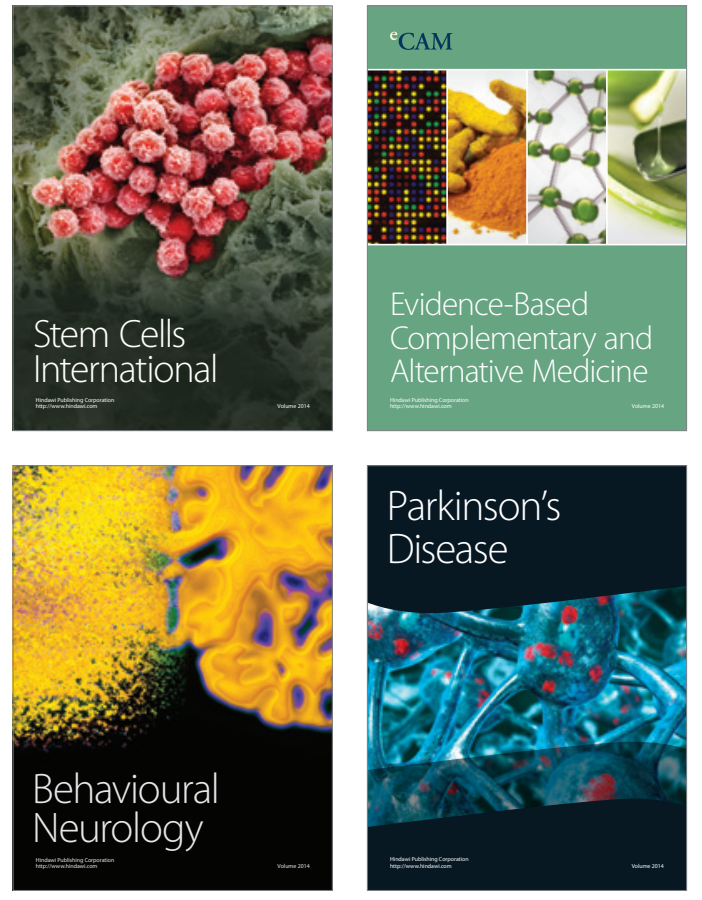
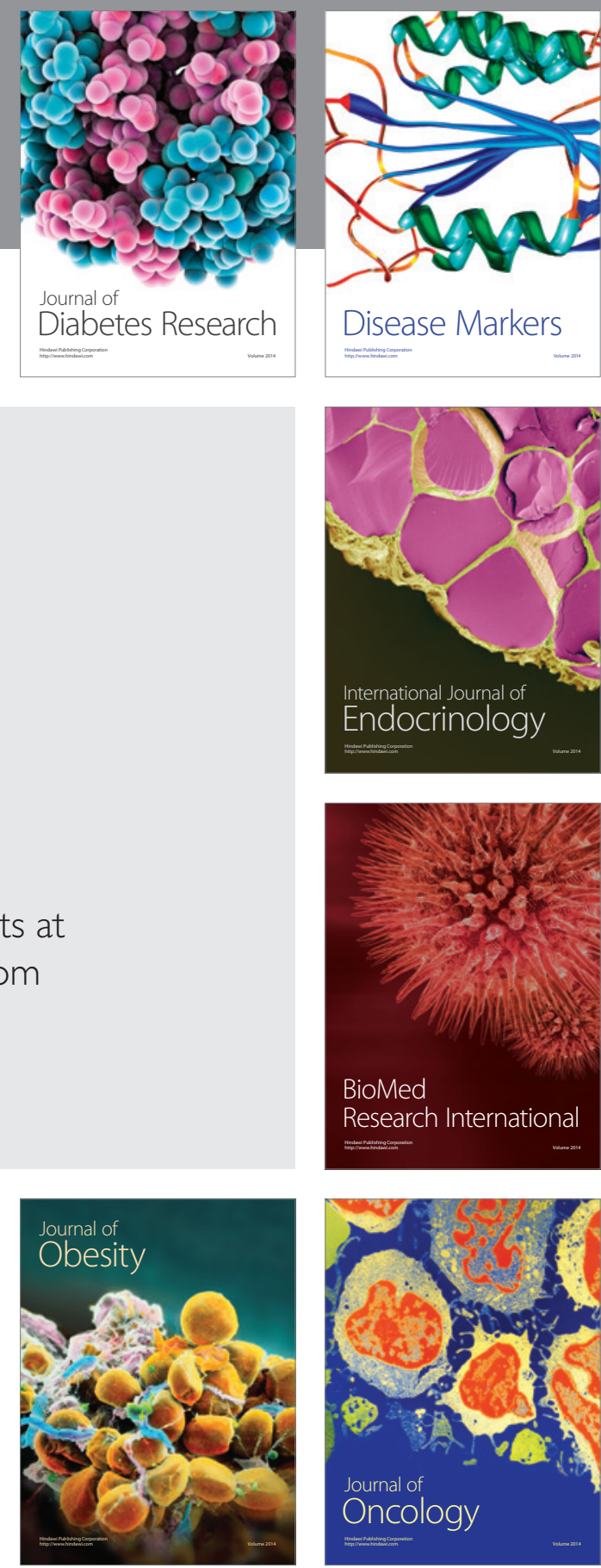

Disease Markers
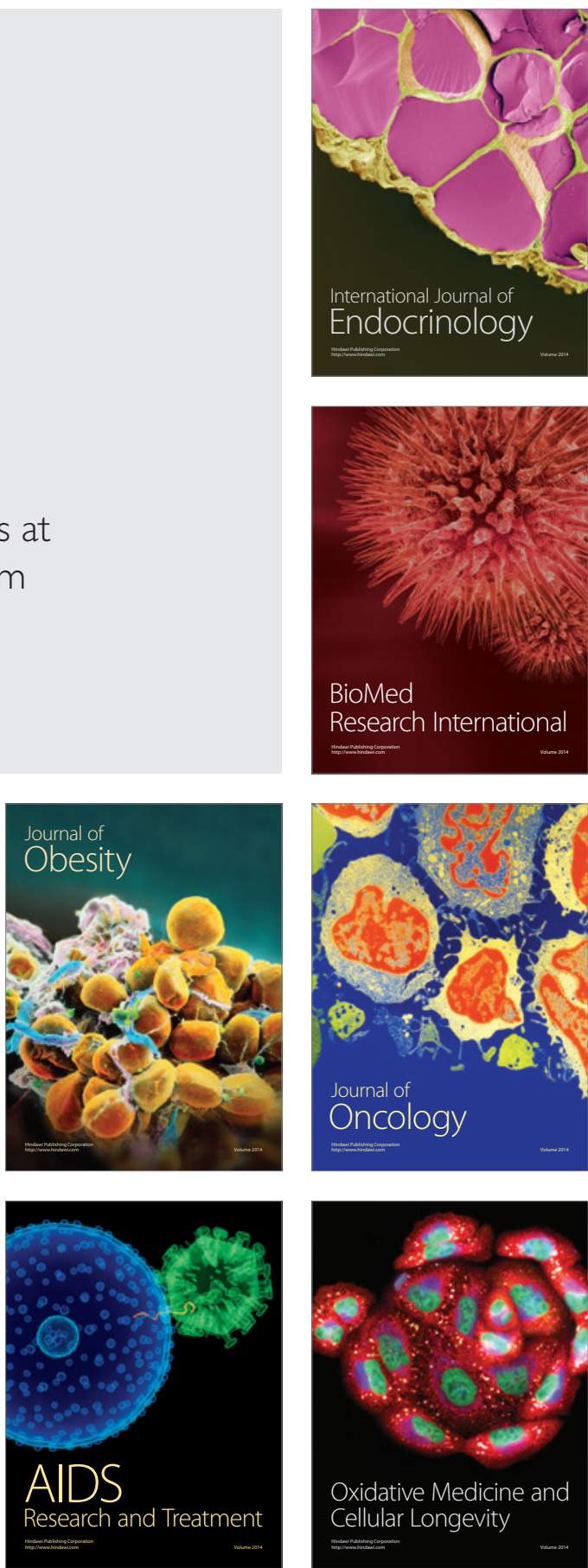